\title{
Adli Olgu Bildirimiyle İlgili İkilemlerde Hekimlerin Tutumları
}

\section{Attitudes of Medical Doctors Towards Conflicting Situations in Forensic Case Declaration}

\author{
İsmail Özgür Can ${ }^{1}$, Mehmet Hakan Özdemir ${ }^{1}$, Neşe Direk ${ }^{2}$ \\ ${ }^{1}$ Dokuz Eylül Üniversitesi Tıp Fakültesi Adli Tıp Anabilim Dall, İzmir \\ ${ }^{2}$ Dokuz Eylül Üniversitesi Tıp Fakültesi Ruh Sağlığı ve Hastalıkları Anabilim Dalı, İzmir
}

\section{Özet}

Amaç: Yasalara göre adli olgu bildiriminde bulunulması gereken bazı durumlarda sağlık çalışanlarının çifte yükümlülükleri gündeme gelmektedir. Hekimler bu durumlarda ikilemler yaşayabilmekte ve yasalarla tıbbi etik ilkelerin çeliştiğini düşünebilmektedir. Bu çalışmada, Dokuz Eylül Üniversitesi Tıp Fakültesi Hastanesi'nde görev yapan hekimlerin adli olgu bildirimi konusundaki haberdarlıkları ve yasalarla tıbbi etik ilkelerin çeliştiğini düşündükleri durumlardaki tutum ve davranışların belirlenmesi amaçlanmıştır.

Gereç ve Yöntem: Yirmi iki sorudan oluşan anket formları ile 106 hekime ulaşılmış; adli olgu tanımı, adli olgu bildirim yükümlülüğü, ilgili yasal ve etik düzenlemeler konusunda haberdarlık, yasa ve etik ilkelerin çeliştiği alanlarda hekimlerin tutum ve davranışları sorgulanmıştır.

Bulgular: Hekimlerin ikilem yaşadığı durumlarla karşı karşıya kaldığında \%62 oranında yasalara, \%35 oranındaysa etik ilkelere uygun hareket ettiği görülmüştür.

Sonuç: İlgili yasalarla tıbbi etik ilkelerin birbiriyle çeliştiği ve desteklediği alanlar tartışılmış olup, tartışmanın ikilem yaratan durumlarda hekimlerin tutum ve davranış değişikliğine katkı sağlayacağı düşünülmüştür.

Anahtar Kelimeler: Adli Olgu Bildirimi; Tıbbi Etik; Çifte Yükümlülük; Adli Tıp; Adli Olgu.

\begin{abstract}
Objective: Dual liability of health professionals occurs in situations in which declaration of forensic case is required. Medical doctors may experience conflicts between legislation and ethical principles. In this study, we aimed to explore the level of knowledge about forensic case declaration of medical doctors working at Dokuz Eylul University School of Medicine. Also, we aimed to determine their attitudes and behaviors towards the situations in which ethical principles and legislation conflict is present to their knowledge.
\end{abstract}

Materials and Methods: We used a 22-item questionnaire including items to evaluate the definition of a forensic case, liability of declaration of forensic case, knowledge about legislation and ethical principles, attitudes and behaviour towards the conflicting situations. In total, 106 medical doctors were evaluated.

Results: Sixty-two percent of medical doctors follow legislation and $35 \%$ of them follow ethical principles when they face with conflicting situations.

Conclusion: We discussed situations in which medical and ethical principles contradict and agree with legislation. We believe that such discussion would be helpful to attitude changes in conflicting situations.

Keywords: Forensic Science; Forensic Case; Declaration of Forensic Case; Dual Liability; Medical Ethics.

\section{Giriş}

Uluslararası Tıp Etiği Kuralları; "Hekim önce hastas1na karşı yükümlüdür ve hastalarına tam bir sadakat borçludur" demektedir. Diğer çıkarlar bu sadakati etkiliyorsa, bir değerler çatışması/çifte yükümlülük ortaya çıkar (1). Çifte yükümlülükler, hekimi hastanın aile bireyleri, işyeri, toplum, yasal makamlar, sigorta ve ilaç şirketleri, tıbbi

Sorumlu Yazar: Yrd. Doç. Dr. Neşe Direk

Dokuz Eylül Üniversitesi Tip Fakültesi Ruh Sağllğg ve Hastalıkları Anabilim Dal, İzmir

E-mail:nese.direk@deu.edu.tr

Geliş: 05.09.2017 Düzeltme: 05.10.2017 Kabul: 20.10.2017 araç üreticileri vb. ile karşı karşıya getirebilir. Adli olgu bildirim yükümlüğü de hastanın mahremiyetinin sağlanması, gizlilik/sır saklama ilkeleriyle çelişebilir.

Yasalara göre adli olgu bildiriminde bulunulması gereken bazı durumlarda sağlık çalışanlarının çifte yükümlülükleri gündeme gelmektedir. Ancak kendisi hakkında adli olgu bildiriminin yapılmasını istemeyen bir hasta ile karşı karşıya kalan hekimler ikilimler yaşayabilmekte ve yasalarla tıbbi etik ilkelerin çeliştiğini düşünebilmektedir. Hasta Hakları Yönetmeliği (Resmî Gazete: 01.08.1998 23420) ve uluslararası tıp etiği ilkeleri gereği hasta hakkındaki tüm tıbbi bilgiler gizlidir ve açıklanması ancak hastanın onayı ile mümkündür (1). 
12 Ekim 2004 tarihli Resmî Gazetede yayınlanan 5237 sayılı Türk Ceza Kanunu'na (TCK) göre ise kamu ve sağlık meslek mensubu çalışanları için adli olgu ile ilgili bildirim yükümlülüğü ile ilgili düzenlemeler şöyledir;

TCK, Madde 279; Kamu görevlisinin suçu bildirmemesi- (1) Kamu adına soruşturma ve kovuşturmayı gerektiren bir suçun işlendiğini göreviyle bağlantılı olarak öğrenip de yetkili makamlara bildirimde bulunmayı ihmal eden veya bu hususta gecikme gösteren kamu görevlisi, altı aydan iki yıla kadar hapis cezası ile cezalandırılır",

TCK, Madde 280; Sağlık mesleği mensuplarının suçu bildirmemesi- (1) Görevini yaptığı sırada bir suçun işlendiği yönünde bir belirti ile karşılaşmasına rağmen, durumu yetkili makamlara bildirmeyen veya bu hususta gecikme gösteren sağlık mesleği mensubu, bir yıla kadar hapis cezası ile cezalandırılır, (2) Sağlık mesleği mensubu deyiminden tabip, diş tabibi, eczacı, ebe, hemşire ve sağlık hizmeti veren diğer kişiler anlaşılır" olarak tanımlanmıştır.

Yasaların sağlık çalışanına getirdiği adli olgu bildirimindeki zorunluluklar, hekimlerin hekimlik uygulamalarında yerine getirmesi beklenen etik ilkelerle çelişir görünmektedir. Hekim hasta ilişkisinin ilk basamağ olan "güvene dayalı ilişki" çerçevesinde hastaya ait öğrenilen tüm bilgilerin gizliliği ve hastanın onamı alınmadan konuları bildirim zorunluluğu ile çelişkilere neden olmakta, hekimlere ikilemler yaşatabilmektedir (2). Bu çalışmada, Dokuz Eylül Üniversitesi Tıp Fakültesi Hastanesi'nde görev yapan hekimlerin adli olgu bildirimi konusundaki haberdarlıkları ve yasalarla tıbbi etik ilkelerin çeliştiğini düşündükleri durumlardaki tutum ve davranışlarının belirlenmesi amaçlanmıştır. Konu evrensel ve yerel yasalar ile tıbbi etik ilkelerin birbiri ile çeliştiği ve desteklediği açılardan tartışılmıştır. Bu çalışmanın adli olgu bildirimi konusunda ikilem yaşanan durumlarda hekimlerin hem yasalara hem de tıbbi etik ilkelere uygun tutum ve davranış geliştirmesine katkı sağlayacağ1 düşünülmüş̧ür.

\section{Gereç ve Yöntem}

Konuyu irdeleyecek 22 sorunun bulunduğu anket formları hazırlandı. Anket formlarında anket yapılacak hekim ile görüşme tarihi, görüşmeye başlamadan önce okunacak bilgilendirme metni, hekimin cinsiyeti, uzmanlık alanı, kıdem yılı, mezuniyet öncesi adli tıp eğitimi alıp almadığı sorularının yanı sıra adli olgu bildirimi konusundaki bilgi ve görüşleri hakkında sorular yer aldı. Kesitsel tipteki çalışmada Dokuz Eylül
Üniversitesi Tıp Fakültesi Hastanesi'nde dahili ve cerrahi bilimlerde çalışan hekimlere ulaşıldı. İlgili açıklamadan sonra anket yapılmasını kabul etmeyenler ve anket sırasında çekilme hakkını kullanmak isteyenler çalışma dışında bırakıldı. Sonuçta toplam 106 hekim çalışmaya dahil edildi ve yüz yüze görüşme yöntemiyle toplanan veriler Windows SPSS 11.0 programında değerlendirildi.

\section{Bulgular}

Çalışmaya dahil olan öğretim üyesi/görevlisi, uzman, uzmanlık öğrencisi 106 hekimin \%40’1 (n=42) kadın, $\% 60$ ' $1(n=64)$ erkekti. Yaş ortalaması 34.47 ( \pm 9.91$)$ (aral1k 23-65) bulundu. Hekimlerin mesleklerinde geçirdikleri süre ortalaması 9.34 \pm 9.74 y1l olup, \%52'si cerrahi bilimlerde, \%48'i dahili bilimlerde çalışıyordu. Hekimlerin \%40’1 öğretim görevlisi/üyesi iken, \%60’^1 tıpta uzmanlık öğrencisiydi. Katılımcıların \%94'ü adli tıp eğitimi almıştı ve $\% 76$ 's " "adli olgu" tanımını biliyordu.

\%65'i meslek yaşamlarında en az bir kez "adli olgu bildiriminde" bulunmuştu, \%35'i ise hiç adli olgu bildirimi yapmamıştı.

Hekimlerin \%96'sı “adli olgu bildirimi” ile ilgili yasal düzenlemeyi (TCK'nın ilgili maddesini) biliyordu. Dahili bilimlerde çalışan hekimlerin \%63'ü muayene sırasında bir suç belirtisi ile karşılaştıklarında adli makamlara bildirim yapmanın yasalara uygun olduğunu bildirirken bu oran cerrahi bilimlerde çalışan hekimlerde $\% 83$ 'e yükseldi ve fark anlamlı olarak bulundu $(\mathrm{p}<0.05)$. Yasal düzenlemelere göre "adli olgu bildirimi" yapılmas1 gereken durumlarda bildirim yapılmadığı zaman yasanın yaptırımını bilmeyenlerin oranı \%79'du. Tablo 1, hekimlerin adli olgu bildirimi ve ilgili yasal düzenlemeler hakkında bilgilerini sorgulayan soruları ve yanıtlarını göstermektedir.

Adli olgu bildirimi ile ilgili olarak bazı durumlarda yasalar ile tıbbi etik ilkelerin çeliştiğini düşünerek, bu durumlarda yasal düzenlemelere göre hareket edeceğini bildiren hekim oranı $\% 58(n=62)$, etik ilkelere göre hareket edeceğini bildiren hekim oranı \%35 ( $\mathrm{n}=37)$ iken $\% 7(n=7)$ gibi bir oranın fikri yoktu (Grafik 1). Tablo 2, çeşitli olgu örneklerine verilen yanıtları ve hekimlerin tıbbi etik ilkelere ne kadar uyduklarını göstermektedir. Tablo 3, adli olgu bildirimi ile ilgili ikilemler yaşandığında hekimlerin tutum ve davranışlarının neler olduğunu sorgulayan sorulara verilen yanıtları göstermektedir. 
Tablo 1. Adli olgu bildirimi ve yasal düzenlemeler ile ilgili sorular

\begin{tabular}{|l|c|c|c|c|c|}
\hline \multirow{2}{*}{ Sorular } & \multicolumn{2}{|c|}{$\begin{array}{c}\text { Doğru } \\
\text { yanıt }\end{array}$} & \multicolumn{2}{|c|}{\begin{tabular}{c}
\multicolumn{2}{|c|}{ yanlış } \\
Tanlam
\end{tabular}} & \multicolumn{2}{|c|}{ Toplay } \\
\cline { 2 - 6 } & n & $\%$ & n & $\%$ & \\
\hline Adli olgu tanımı? & 80 & 76 & 25 & 24 & 105 \\
\hline $\begin{array}{l}\text { Bildirim yükümlülüğ̈̈ } \\
\text { hangi yasal } \\
\text { düzenlemede yer alır? }\end{array}$ & 97 & 91 & 9 & 9 & 106 \\
\hline $\begin{array}{l}\text { Bildirim yapılmazsa } \\
\text { hekime yaptırımı } \\
\text { nedir? }\end{array}$ & 22 & 21 & 83 & 79 & 105 \\
\hline $\begin{array}{l}\text { Adli olgu bildirimi } \\
\text { nereye yapılır? }\end{array}$ & 42 & 40 & 63 & 60 & 105 \\
\hline $\begin{array}{l}\text { Adli olgu bildirimi } \\
\text { ilgili makamlara nasıl } \\
\text { yapılır? }\end{array}$ & 87 & 82 & 19 & 18 & 106 \\
\hline
\end{tabular}

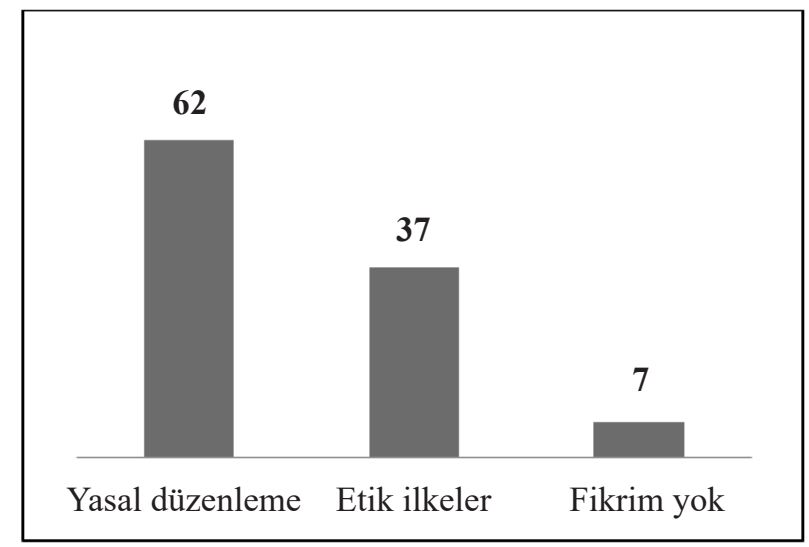

Grafik 1. Tibbi etik ile yasal düzenlemeler arasında ikilemler yaşadığında hekimlerin meslek uygulamaları

Tablo 2. Adli olgu bildirimi ile ilgili tıbbi etik ilkeleri sorgulayan sorular

\begin{tabular}{|l|c|c|c|c|c|}
\hline \multirow{2}{*}{ Sorular } & \multicolumn{2}{|c|}{ Evet } & \multicolumn{2}{|c|}{ Hayır } & Toplam \\
\cline { 2 - 6 } & $\mathbf{n}$ & $\mathbf{\%}$ & $\mathbf{n}$ & $\mathbf{\%}$ & \\
\hline Sanık, şüpheli veya mağduru hasta olarak kabul eder misiniz? & 103 & 97 & 3 & 3 & 106 \\
\hline $\begin{array}{l}\text { Bel ağrısı şikâyetiyle gelen kadın hastanın muayenesinde sırtta 4 adet eski yanık izi } \\
\text { gözlediniz. Aile içi şiddet mağduru olarak düşünüp, adli olgu bildirimi yapar mısınız? }\end{array}$ & 53 & 52 & 50 & 48 & 103 \\
\hline $\begin{array}{l}\text { Acilde hekimsiniz, polis memuru künt travma nedeniyle getirdiği hasta için } \\
\text { adli rapor düzenlemenizi talep ediyor. Adli olgu bildirimi yapmadan adli rapor } \\
\text { düzenler misiniz? }\end{array}$ & 91 & 88 & 12 & 12 & 103 \\
\hline $\begin{array}{l}\text { 14 yaşında resmi nikâhlı olmayan eşiyle beraber kliniğinize boğaz ağrısı şikâyeti ile } \\
\text { gelen kadın hastanın gebe olduğunu fark ettiniz. Adli olgu olarak düşünüp, bildirim } \\
\text { yapar mısınız? }\end{array}$ & 75 & 73 & 28 & 27 & 103 \\
\hline
\end{tabular}

Tablo 3. Adli olgu bildiriminde ikilemler yaşanan olgulara verilen yanıtlar

\begin{tabular}{|c|c|c|c|c|c|c|c|}
\hline \multirow[t]{2}{*}{ Sorular } & \multicolumn{2}{|c|}{$\begin{array}{c}\text { Yasalara uygun } \\
\text { davranış }\end{array}$} & \multicolumn{2}{|c|}{$\begin{array}{l}\text { Etiğe uygun } \\
\text { davranış }\end{array}$} & \multicolumn{2}{|c|}{ Fikrim yok } & \multirow[t]{2}{*}{ Toplam } \\
\hline & $\mathrm{n}$ & $\%$ & $\mathbf{n}$ & $\%$ & $\mathbf{n}$ & $\%$ & \\
\hline $\begin{array}{l}\text { Hekimlik uygulaması sırasında suç belirtisi ile } \\
\text { karşılaşıldığında hepsi adli olgu olarak bildirilmeli } \\
\text { midir? Aydınlatılmış onam alınmalı mıdır? }\end{array}$ & 77 & 73 & 17 & 16 & 12 & 11 & 106 \\
\hline $\begin{array}{l}\text { İntihar girişimi olan olguların hepsi adli olgu olarak } \\
\text { kabul edilebilir mi? }\end{array}$ & 82 & 79 & 7 & 7 & 15 & 14 & 104 \\
\hline $\begin{array}{l}17 \text { yaşında kadın hasta, erkek arkadaşı ile cinsel } \\
\text { ilişkiye girdiğini bildiriyor. Vajinal akıntı şikâyeti } \\
\text { var. Muayene yapılırken annesi dışarıda bekliyor. } \\
\text { Hasta zihinsel olarak yeterli ve bu konuyu } \\
\text { kimsenin bilmesini istemediğini söylüyor. Adli olgu } \\
\text { bildiriminde bulunur musunuz? }\end{array}$ & 24 & 23 & 72 & 69 & 8 & 8 & 104 \\
\hline
\end{tabular}


Hekimlerin \%77'si adli olgu bildirimi yaparken hastanın aydınlatılmış onamını almaya gerek olmadığını, yasalar çerçevesinde bildirimin zorunlu olduğunu belirtmişti.

\section{Tartışma}

Hastanın kendini tedavi edecek hekime olan güveni "hekim hasta ilişkisinin" en temel basamağıdır ve bu güvene dayalı ilişkide hekimin hastadan öğrendiği tüm bilgilerin gizli kalacağının varsayılması hukuki niteliğe de sahiptir.

Hekimlerin hekimlik uygulamaları sırasında uymakla yükümlü oldukları meslek ilkelerini düzenleyen; Dünya Hekimler Birliği (DHB) Tıp Etiği Kuralları (1), Hasta Hakları Yönetmeliği; m. 20 (Resmi Gazete: 01.08.1998 23420), T1bbi Deontoloji Tüzüğü; m.4 (Tıbbi Deontoloji Tüzüğü, Resmi Gazete: 19 Şubat 1960 - Sayı: 10436), Türk Tabipleri Birliği (TTB) Meslek Etiği Kuralları; m.9 (3), Türkiye Psikiyatri Derneği Ruh Hekimliği (Psikiyatri) Meslek Etiği Kuralları; m. 6 (4) da hekiminin sır saklama borcunu düzenlemektedir. Hekimlik meslek etiğine göre sir saklamak DHB etik bildirgelerinde de (Cenevre 1948, Lizbon 1981, Venedik 1983) dile getirilmiş, hekimin öldükten sonra bile hastasına ait bilgileri saklamaya özen göstermesi önerilmiştir.

Ancak hekimlik uygulamalarında adli olgu niteliği taşıyan veya uygulama sırasında bir suç belirtisi ile karşılaşılan olguların yasal düzenlemelere göre bildirimi zorunlu kılınmıştır. TCK 280. maddesi; bir suç belirtisi ile karşılaşıldığında sağlık çalışanlarına bildirim zorunluluğunu getirmektedir. $\mathrm{Bu}$ zorunluluk hekimlik uygulamalarında bazı durumlarda etik ilkeler ile çelişir görünmektedir. Hem etik ilkeler çerçevesinde hasta bilgilerinin gizliliği ve hekimin sır saklama yükümlülüğü vurgulanmakta, bilgilerin hastanın rızası olmadan açıklanamayacağı bildirilmekte, hem de ilgili yasa maddesine göre bildirim zorunlu kılınmaktadır. Bu durum hekimlik uygulamalarında ikilemler yaşatmaktadır.

Aslında farklı yasal düzenlemelerde de çelişkiler görülmektedir. Ceza Muhakemesi Kanunu'nun (CMK) 46. maddesinde (Ceza Muhakemesi Kanunu, Kanun No: 5271, Resmî Gazete: 17 Aralık 2004, Sayı: 25673); hekimlerin sır saklama yükümlülüğünü yerine getirebilmesi için sağlık çalışanlarına tanıklıktan çekinme hakkını tanımıştır. TCK'nın 134. maddesinde ise "özel hayatın gizliliği ihlali" ile de gizliliği ihlal eden kişi cezalandırılmaktadır. Avrupa Biyotıp Sözleşmesi'nin 10. maddesinde (5) ise; "1. Herkes, kendi sağlığıyla ilgili bilgiler bakımından, özel yaşamına saygı gösterilmesini isteme hakkına sahiptir" denilmektedir.

TCK'nın 280. maddesinde önceki yasal düzenlemede olduğu gibi "önce müdahale sonra bildirim" ilkesi yer almamaktadır. Hekimin asli görevi ise önce zarar vermemek ve hastasını tedavi etmek iken ilgili yasa maddesi sağlık çalışanlarında ceza tehdidi algısına yol açmıştır. Hatta, TCK'nın 235. maddesinde bir suç işlendiğini öğrendiği halde yetkili mercilere bildirmede ihmal ve gecikme gösteren memurlar için 4 aydan 2 yıla kadar hapis cezası da öngörülmüştür.

Adli olgu bildirim yükümlüğü konusunda etik ve yasal düzenlemeler arasındaki çelişkiler nedeniyle; hekimlerin adli olgu bildirimi konusunda haberdarlıkları ve ikilem yaşanılan konularda tutum ve davranışlarını tespit etmek ve sonuçlar üzerinden tartı̧̧mak amaçlanmıştır. Daha önce yapılan çalışmalarda hekimlerin çeşitli nedenlerle (adli tıp eğitiminin yetersizliği, bilgisizlik, deneyimsizlik, sorumsuzluk, ilgisizlik) adli rapor düzenlemekten kaçındıkları ve bildirim konusunda sıkıntılar yaşadıkları bildirilmiştir (6-8). Tuğcu ve ark. çalışmasinda (9) asistan hekimlerin \%53'ünde adli olgu bildirimi hakkında hiçbir bilgi olmadığı, acil serviste çalışanların \%8'inde ise adli olgu bildirimi ile ilgili sorunlar yaşandığı bahsedilmektedir. Pratisyen hekimlerin adli tıp uygulamalarında yaşadığı sorunları çalışan bir başka çalışmada hekimlerin \%78'inin yasal mevzuatı yeterince bilmediği ifade edilmiştir (10). Dokuz Eylül Üniversitesi Tıp Fakültesi Hastanesi'nde çalışan 106 hekimin katıldığı bu çalışmada ise hekimlerin \%97'sinin “adli olgu bildirim yükümlülüğü” ile ilgili yasal düzenlemeyi bildiği, ancak \%83'ünün yasal düzenleme hakkında yeterli bilgiye sahip olmadığı belirlendi. Ayrıca katılımcıların \%94'ünün adli tıp eğitimini aldığ ve \%76'sının "adli olgu" tanımını bildiği anlaşıldı. Bununla birlikte adli olgu bildiriminin nereye ve nasıl yapılacağı ile ilgili detay sorularda yanlış yanıt oranının yüksekliği adli tıp eğitiminde sorunları da akla getirmiştir (Tablo 1). Birçok çalışmada hekimlerin adli tıp eğitiminin yeterli olmadığı dile getirilmiştir (6-9).

Bu yasal düzenlemelerin sonucunda mevcut ikilemlerin en önemli öznelerinden biri olan psikiyatri hekimleri ve psikologlarla yapılan bir çalışmada (11), psikolog ve psikiyatristlere hasta sırrını açıklama inisiyatifi kendilerine bırakılsa bu sırları adli makamlara açıklayıp açıklamayacakları sorulmuştur. Psikiyatristlerin \%92,8'i, psikologlarınsa \%7,2'si bu soruya hayır yanıtını vermiştir. Yine aynı çalışmada hastanın suç işlediğini beyan etmesi halinde bu bilginin adli makamlardan saklanıp saklanmaması gerektiği yönündeki soruya gerek psikolog gerekse psikiyatristler $\% 90$ oranında hayır yanıtını vermiştir. $\mathrm{Bu}$ çalışmada elde edilen veriler bu konuda belirli düzeyde bir duyarlılık olmakla birlikte, özellikle adli tıp eğitimi olmayan psikologların bu alanda kuramsal açıdan daha zayıf olduklarını göstermektedir. 
Hekimlerin özellikle yasa ve tıbbi etik ilkelerin çeliştiğini düşündüğü ve ikilemler yaşayabileceği sorulara verilen yanıtlar, tıp etiği ile yasalar konusunda yeterli bilgiye sahip olmadıklarını da düşündürmektedir (Tablo 2 ve 3). Hekimlerin hasta hakkındaki gizli tıbbi bilgilerin açıklanmasının etik ilkelerle bağdaşmayacağı durumlarda bildirimde bulunmayı tercih ettikleri gözlenmiştir. Cerrahi bilimlerde çalışan hekimlerin \% $\% 7^{\prime}$ 'i, 17 yaşında cinsel ilişki öyküsü veren bir hastada adli olgu olarak bildirim yapmayacağını, hastanın tedavisini düzenlemekle yetineceğini belirtirken dahili bilimlerdeki hekimlerde bu oranın \%60'lara düştüğü gözlendi.

Sağlık çalışanları için düzenlenen bildirim yükümlügü halk sağlığını ilgilendiren konularda tedbir almak ve "kamu yararını" gözetirken temel hasta haklarını ihlale neden olabilmektedir. Hekimlerin birincil görevi hasta yararı ve sağlığı ile ilgilenmektir, suçların önlenmesine yardımcı olma görevi olan "ihbar yükümlülüğü" ise ikincil görev olmalı ve hekimlik uygulamalarına engel olmamalıdır.

Avrupa Biyotıp Sözleşmesi, 2003 yılında onaylanarak kanun hükmündedir ve T.C. Anayasası'nın 90. maddesi kapsamında güvence altına alınmıştır (Türkiye Cumhuriyeti Anayasası, Kanun No: 2709, Resmî gazete; 09.11.1982-17863). Buna göre;

"Usulüne göre yürürlüğe konulmuş milletlerarası andlaşmalar kanun hükmündedir. Bunlar hakkında Anayasaya aykırılık iddiası ile Anayasa Mahkemesine başvurulamaz. Usulüne göre yürürlüğe konulmuş temel hak ve özgürlüklere ilişkin milletlerarası andlaşmalarla kanunların aynı konuda farklı hükümler içermesi nedeniyle çıkabilecek uyuşmazlıklarda milletlerarası andlaşma hükümleri esas alınır." denilmektedir.

Bazı durumlarda bildirim yükümlülüğünü düzenleyen TCK'nın 280. maddesi her zaman geçerli olmayabilir, dolayısı ile tıbbi etik ilkeler çerçevesinde "önce zarar verme, hasta yararı, gizlilik ve sır saklama, hasta rızasının olmaması" konuları öncelik kazanabilir.

\section{Sonuç}

Adli olgu bildirimi ve adli rapor düzenleme hekimin mesleki ve hukuki sorumluluğudur. Ancak bazı durumlarda bildirim zorunluluğu tıbbi etik ilkelerle çelişebilir. Bu çalışmada; özellikle etik ilkelerle yasal düzenlemelerin çelişir göründüğü durumlarda ve yaşanan ikilemlerde tıbbi etik ilkelere uygun davranmanın Avrupa Biyotıp Sözleşmesi ve Anayasa'nın 90. maddesi ile güvence alt1na alındığı hatırlatmak istenmiştir.

Tıp etiği ve adli olgu, muayene süreçleri ve yasal çerçeve konularına tıp eğitimi ve mezuniyet sonrası eğitimlerde daha geniş yer verilmesi uygun olacaktır.

\section{Bildirimler}

Yazıda yer alan fikirler yazarların kendilerine ait görüşler ve bilimsel veriler ya da ulusal/uluslararası bildirge, tutum belgeleri ya da yasalarla desteklenen düşüncelerdir.

Yazarlar çıkar çatışması bildirmemektedir.

Çalışmada herhangi bir mali kaynak kullanılmamıştır.

Not:“Çalışmamızın istatistik bölümünde, yaptığı katkılardan dolayı DEÜ Fen Fakültesi istatistik Bölümü öğretim üyesi Firat Özdemir'e ve ÖÇM öğrencileri Barış Can Atlı, Emre Yoldaş, Gizem Gençoğlu, Selim Yiğit Erçetin, Elif Aşıcı, Esra Hündür, Ferhat Coşkun'a ve Uzm.Dr. Uğur Kavaklı'ya teşekkür ederiz."

\section{Kaynaklar}

1. Dünya Hekimler Birliği Tıp Etiği Elkitabı, TTB yayınları, 2005, Ankara, http://www.ttb.org.tr/kutuphane/tip_etigi.pdf, (TTB web sitesi), Erişim tarihi; 21.05.2012.

2. Çetin G, Yorulmaz C. Yeni Yasalar Çerçevesinde Hekimlerin Hukuki ve Cezai Sorumluluğu, Tıbbi Malpraktis ve Adli Raporların Düzenlenmesi. Korur Fincancı Ş. Adli Olguya Yaklaşım, s.92-103. İ.Ü. Cerrahpaşa Tip Fakültesi Sürekli Tip Eğitimi Etkinlikleri Sempozyum Dizisi no:48, 2006, İstanbul.

3. TTB Hekimlik Meslek Etiği Kurallar1; 1999, http://www. ttb.org.tr/index.php/meslek-etigi.html, (TTB web sitesi), Erişim tarihi; 22.05.2012.

4. Ruh Hekimi (Psikiyatri) Meslek Etiği Kuralları http://www. psikiyatri.org.tr/upload.aspx?upload=311, (TPD web sitesi), Erişim tarihi; 22.05.2012.

5. Biyoloji ve Tibbın Uygulanması Bakımından İnsan Haklar1 ve İnsan Haysiyetinin Korunması Sözleşmesi: İnsan Hakları ve Biyotıp Sözleşmesinin Onaylanmasının Uygun Bulunduğuna Dair Kanun. Kanun No: 5013, Resmi Gazete: 09.12.2003- Say1: 25311, http://www.biyoetik.org.tr/mevzuat/Uluslararasi/Biyotip.htm, Erişim tarihi; 22.05.2012.

6. Tümer AR, Keten A, Karacaoğlu E. Adli olgu bildirimi ve adli raporlar. Hacettepe Tip Dergisi 2010;41:128-34.

7. Türkmen N, Akgöz A, Çoltu A, Ergin N. Uludağ Üniversitesi Tıp Fakültesi Acil Servisine başvuran adli olguların değerlendirilmesi. Uludağ Üniversitesi Tip Fakültesi Dergisi 2005;31(1):25-9.

8. Turla A, Dündar C. Samsun il merkezinde adli rapor düzenleyen pratisyen hekimlerin adli tıp eğitimi ve adli raporlara yansımaları. Ondokuz Mayıs Üniversitesi Tıp Dergisi 2003;20:119-24.

9. Tuğcu H, Yorulmaz C, Ceylan S, Baykal B, Celasun B, Koç S. Acil servis hizmetine katılan hekimlerin, acil olgularda hekim sorumluluğu ve adli tıp sorunları konusundaki bilgi ve düşünceleri. Gülhane Tıp Dergisi 2003;45:175-9.

10. Gündüz T. Pratisyen hekimlerin adli tıp uygulamalarında karşılaştıları sorunları. Türkiye Klinikleri Tıbbi Etik 1997;5:56-63.

11. Çayköylü A, İbiloğlu A. Türkiye'de ruh sağlığı çalışanlarının sır saklama ile ilgili düşünce ve yaklaşımları. Anadolu Psikiyatri Dergisi 2009;10(EK 1):89-91. 